\title{
Duplication, concerted evolution and purifying selection drive the evolution of mosquito vitellogenin genes
}

\author{
Song Chen', Jennifer S Armistead' ${ }^{1}$, Katie N Provost-Javier'1, Joyce M Sakamoto² and Jason L Rasgon*1,3
}

\begin{abstract}
Background: Mosquito vitellogenin (Vtg) genes belong to a small multiple gene family that encodes the major yolk protein precursors required for egg production. Multiple Vtg genes have been cloned and characterized from several mosquito species, but their origin and molecular evolution are poorly understood.

Results: Here we used in silico and molecular cloning techniques to identify and characterize the evolution of the Vtg gene family from the genera Culex, Aedes/Ochlerotatus, and Anopheles. We identified the probable ancestral Vtg gene among different mosquito species by its conserved association with a novel gene approximately one kilobase upstream of the start codon. Phylogenetic analysis indicated that the Vtg gene family arose by duplication events, but that the pattern of duplication was different in each mosquito genera. Signatures of purifying selection were detected in Culex, Aedes and Anopheles. Gene conversion is a major driver of concerted evolution in Culex, while unequal crossover is likely the major driver of concerted evolution in Anopheles. In Aedes, smaller fragments have undergone gene conversion events.

Conclusions: The study shows concerted evolution and purifying selection shaped the evolution of mosquito Vtg genes following gene duplication. Additionally, similar evolutionary patterns were observed in the Vtg genes from other invertebrate and vertebrate organisms, suggesting that duplication, concerted evolution and purifying selection may be the major evolutionary forces driving Vtg gene evolution across highly divergent taxa.
\end{abstract}

\section{Background}

Vitellogenin $(V t g)$ genes encode the major yolk protein precursors which are utilized in oviparous organisms to provide nutrition for the developing embryo. In oviparous vertebrates, Vtgs are synthesized in the liver of the mature female under the control of estrogen, secreted into the bloodstream, transported to the ovary and selectively taken up by the oocytes [1,2]. In insects, Vtgs are synthesized primarily in the fat body of female adults under the regulation of juvenile hormone and/or 20hydroxyecdysone (20E), secreted into the hemolymph and taken up by the developing oocytes via receptormediated endocytosis [3-8].

\footnotetext{
* Correspondence: jrasgon@jhsph.edu

1 The W. Harry Feinstone Department of Molecular Microbiology and Immunology, Bloomberg School of Public Health, Johns Hopkins University, Baltimore, MD, 21205, USA

Full list of author information is available at the end of the article
}

The female adults of many mosquito species require a vertebrate blood meal to develop eggs, leading to the transmission of a variety of pathogens in humans, wildlife and domestic animals. Understanding the molecular mechanism of blood meal or nutrition-induced synthesis of $V t g$ proteins may lead to insights for novel mosquito control strategies. Great gains have been made in understanding the mechanisms that regulate blood mealinduced vitellogenesis the mosquito Aedes aegypti. The cDNA encoding the Ae. aegypti VgA1 gene has been characterized and its genomic sequence containing $2015 \mathrm{bp}$ of the $5^{\prime}$ promoter region cloned $[9,10]$. Studies on transcriptional expression and regulation identified a combination of nutritional stimuli (free amino acids) and the steroid hormone $20 \mathrm{E}$ as the key factors required for activation of vitellogenesis. The expression of Vtgs and other yolk precursor protein (YPP) genes is inhibited by the AaGATAr transcription factor during the previtellogenic period. After digesting a blood meal, amino acids are 
released from the midgut and activate the TOR signalling pathway in the fat body, resulting in the subsequent derepression of YPP gene transcription by displacing AaGATAr with another GATA factor [11-16]. Since mosquito $V t g$ synthesis is activated by a blood meal in a sex-, tissue-, and stage-specific manner, its promoter region has been used to control the precise temporal and spatial expression of exogenous genes (such as anti-pathogen effector molecules) in engineered mosquitoes [17-20].

Recently, several new Vtg gene sequences were isolated from several mosquito species including Anopheles albimanus, Ae. aegypti, Ae. polynesiensis, Ae. albopictus, Ochlerotatus atropalpus, Oc. triseriatus, Culex pipiens and Toxorhynchites amboinensis [21]. Comparative sequence analysis performed among three $V t g$ genes from $A e$. aegypti suggested that $V g-A 1$ and $V g-B$ were closely related and possibly arose by a recent gene duplication event, while $V g-C$ was distantly related to the $V g-A 1$ and $V g-B$ lineage, and possibly arose by an earlier gene duplication event [21]. Nevertheless, the study of the evolution of the $V t g$ gene family among mosquitoes in general is still limited. In this paper, we used in silico and molecular cloning techniques to identify and characterize the evolution of the Vtg gene family from the genera Culex, Aedes, Ochlerotatus and Anopheles. We were also able to identify the probable ancestral Vtg gene copy among mosquito genera.

\section{Results}

Isolation of mosquito $\mathrm{Vtg}$ genes by in silico whole genome analysis and molecular cloning

The release of the whole genome sequences of $C x$. pipiens, Ae. aegypti and An. gambiae enabled us to analyze the genomic organization of $V t g$ genes and examine their evolutionary pattern across mosquito genera. By using a $V t g$ gene from Ae. aegypti (GenBank accession L41842) as query to BLAST search the Cx. pipiens whole genome sequence, four intact Vtg genes were identified, designated as CpVgla (GenBank accession NZ_AAWU01017720), CpVg1b (GenBank accession NZ AAWU01017726), $C p V g 2 a$ and $C p V g 2 b$ (GenBank accession AAWU01001936) ("Cp" refers to the first letters of genus and species name; other mosquito $V t g$ genes in the following text are designated in a similar fashion). Each of these genes contained a different sequence in their 5 ' promoter regions, indicating they were positioned at different genomic loci. $C p V g 2 a$ and $C p V g 2 b$ were clustered together and organized in a "tail-to-tail" orientation with an intergenic region of 5,113 bp. It was not clear whether $C p V g 1 a$ and $C p V g 1 b$ were clustered due to limitations in the genome assembly. The two Vtg families CpVg1 and CpVg2 shared 64.8\%-65.7\% nucleotide identity, while subfamily $C p V g 1 a$ and $C p V g 1 b$ shared extremely high nucleotide identity (98.9\%), as did $C p V g 2 a$ and $C p \operatorname{Vg} 2 b$ (98.4\%) (Table 1).

BLAST searches revealed three $V t g$ genes in the $A e$. aegypti genome sequence (AeVgA, accession AAGE02018519; $A e V g B$, accession AAGE02009986 and $A e V g C$, accession AAGE02009985), consistent with previous studies $[9,10,21]$. Based on the genome sequence data, we determined the organization of these three genes. $A e V g B$ and $A e V g C$ were located in the same super contig (supercont1.191) with an intergenic region of approximately $115 \mathrm{~kb}$ (super contig location; $A e V g B$ : 160,790-167,359; $\mathrm{AeVgC}$ : 39,434-45,832), while AeVgA was located in a different supercontig (supercont1.477) (VectorBase). These three genes shared $61.4 \%-88.4 \%$ nucleotide identity.

BLAST searches revealed three $V t g$ genes from whole genome sequence of An. gambiae (ACCESSION AAAB01008880) and non-redundant database in GenBank (ACCESSION AF281078). The former encoded three $V t g$ genes ( $A g V g 1, A g V g 2$ and $A g V g 3$ ), but with partial coding sequence for $A g V g 1$ and $A g V g 2$; the later encoded $A g V g 1$ and $A g V g 2$ with partial sequence for $A g V g 2$. The $A g V g 2$ sequence was partial due to a genome sequence gap, but by combining data from both datasets we obtained intact sequences for $A g V g 1$ and $A g V g 3$ (Figure 1). All three $V t g$ genes showed extremely high nucleotide identity (98.1\%-99.2\%) and are encoded as a tandem repeat in the An. gambiae genome (Figure 1).

When we attempted to isolate and clone the 5 promoter region of the Cx. tarsalis Vtg gene, the obtained sequence data lead us to identify four different loci that had high conservation in the coding sequence but unique 5 '-promoter regions. On the basis of the Cx. pipiens Vtg gene coding sequence, multiple sets of primers were designed to isolate the intact Vtg genes from $C x$. tarsalis. We first cloned the partial coding sequences and then obtained the $5^{\prime}$ and 3 ' end fragments. Specific primers located in the $5^{\prime}$ promoter region and $3^{\prime}$ coding or $3^{\prime} \mathrm{UTR}$ regions were designed to amplify the full length genes. Four full length $V t g$ genes from $C x$. tarsalis were isolated, designated as CtVg1a, CtVg1b, CtVg2a and CtVg2b. Sequence analysis indicated that the two Vtg families CpVg1 and CpVg2 shared 64.3\%-65.5\% nucleotide identity, while subfamily CtVg1a and CtVg1b shared extremely high nucleotide identity (98.1\%), as did CtVg2a and $C t V g 2 b$ (97.0\%) (Table 1).

Identification of the ancestral Vtg gene copy in mosquitoes While isolating the 5'-promoter region of the CtVglb gene, we identified a novel gene $805 \mathrm{bp}$ upstream of the CtVglb start codon, in the opposite orientation. This small gap between the start codons of the novel gene and $C t V g 1 b$ suggests that this region may act as a bidirectional promoter. The novel gene contained two putatively 
Table 1: Pairwise nucleotide similarity comparisons of Culex Vtg genesa.

\begin{tabular}{|c|c|c|c|c|c|c|c|c|}
\hline & CtVg1a & CtVg1b & CtVg2a & $C t V g 2 b$ & CpVg1a & $C p V g 1 b$ & CpVg2a & $C p V g 2 b$ \\
\hline \multicolumn{9}{|c|}{5 'end/3'end } \\
\hline CtVg1a & - & 97.6 & 43.5 & 45.9 & 84.3 & 85.0 & 44.1 & 45.3 \\
\hline CtVg1b & NM & - & 43.2 & 45.6 & 83.5 & 84.3 & 45.2 & 45.3 \\
\hline$C t \operatorname{Vg} 2 a$ & NM & NM & - & 94.6 & 44.4 & 45.8 & 73.9 & 72.5 \\
\hline$C t \operatorname{Vg} 2 b$ & NM & NM & NM & - & 47.3 & 47.3 & 74.0 & 72.7 \\
\hline CpVg1a & NM & NM & NM & NM & - & 99.2 & 45.9 & 44.5 \\
\hline CpVg1b & NM & NM & NM & NM & 100 & - & 45.3 & 44.5 \\
\hline CpVg2a & NM & NM & NM & NM & NM & NM & - & 96.5 \\
\hline$C p V g 2 b$ & NM & NM & NM & NM & NM & NM & NM & - \\
\hline \multicolumn{9}{|c|}{ Exon1/Exon2 } \\
\hline CtVg1a & - & 100 & 62.5 & 62.5 & 100 & 100 & 62.5 & 62.5 \\
\hline CtVg1b & 98.1 & - & 62.5 & 62.5 & 100 & 100 & 62.5 & 62.5 \\
\hline CtVg2a & 65.7 & 65.8 & - & 100 & 62.5 & 62.5 & 100 & 100 \\
\hline$C t V g 2 b$ & 65.7 & 65.7 & 97.5 & - & 62.5 & 62.5 & 100 & 100 \\
\hline CpVg1a & 91.3 & 91.8 & 66.5 & 66.3 & - & 100 & 62.5 & 62.5 \\
\hline$C p V g 1 b$ & 91.6 & 91.9 & 66.4 & 66.3 & 98.7 & - & 62.5 & 62.5 \\
\hline CpVg2a & 65.9 & 66.0 & 90.4 & 91.0 & 66.8 & 66.9 & - & 100 \\
\hline$C p V g 2 b$ & 65.8 & 65.9 & 90.2 & 90.9 & 66.6 & 66.7 & 99.6 & - \\
\hline \multicolumn{9}{|c|}{ Intron1/Intron2 } \\
\hline CtVgla & - & 93.8 & 57.1 & 57.1 & 81.5 & 81.8 & 53.5 & 53.5 \\
\hline CtVg1b & 88.5 & - & 55.1 & 56.9 & 83.1 & 83.1 & 54.3 & 54.3 \\
\hline CtVg2a & 52.0 & 54.7 & - & 93.6 & 52.7 & 56.0 & 75.4 & 75.4 \\
\hline$C t V g 2 b$ & 52.0 & 54.7 & 100 & - & 54.1 & 54.7 & 70.8 & 70.8 \\
\hline CpVg1a & 66.7 & 68.8 & 57.9 & 57.9 & - & 90.6 & 53.4 & 53.4 \\
\hline$C p V g 1 b$ & 69.7 & 72.7 & 55.1 & 55.1 & 92.3 & - & 51.4 & 51.4 \\
\hline CpVg2a & 50.7 & 51.3 & 63.3 & 63.3 & 52.0 & 51.3 & - & 100 \\
\hline$C p V g 2 b$ & 51.3 & 52.0 & 64.6 & 64.6 & 51.4 & 51.3 & 98.7 & - \\
\hline \multicolumn{9}{|c|}{ Exon3/Entire coding region } \\
\hline CtVg1a & - & 98.3 & 64.6 & 64.7 & 92.3 & 92.2 & 65.5 & 65.3 \\
\hline CtVg1b & 98.1 & - & 64.9 & 65.1 & 92.3 & 92.2 & 66.1 & 65.8 \\
\hline CtVg2a & 65.5 & 64.6 & - & 94.6 & 63.8 & 64.0 & 86.6 & 85.8 \\
\hline$C t V g 2 b$ & 64.3 & 64.5 & 97 & - & 64.0 & 64.1 & 84.8 & 87.8 \\
\hline CpVg1a & 91.4 & 91.9 & 64.8 & 64.8 & - & 99.4 & 65.3 & 64.6 \\
\hline$C p V g 1 b$ & 91.6 & 91.9 & 64.8 & 64.8 & 98.9 & - & 65.6 & 64.9 \\
\hline CpVg2a & 64.8 & 65.0 & 89.7 & 89.7 & 65.6 & 65.7 & - & 92.9 \\
\hline$C p V g 2 b$ & 64.7 & 64.9 & 90.3 & 90.3 & 65.3 & 65.4 & 98.4 & - \\
\hline
\end{tabular}

a Above the diagonal shows percentages of nucleotide identity in 5'end, exon 1, intron 1 and exon3; below the diagonal shows the percentages of nucleotide identity in the 3'UTR, exon2, intron2 and putative total converted sequences NM: represents no significant match 


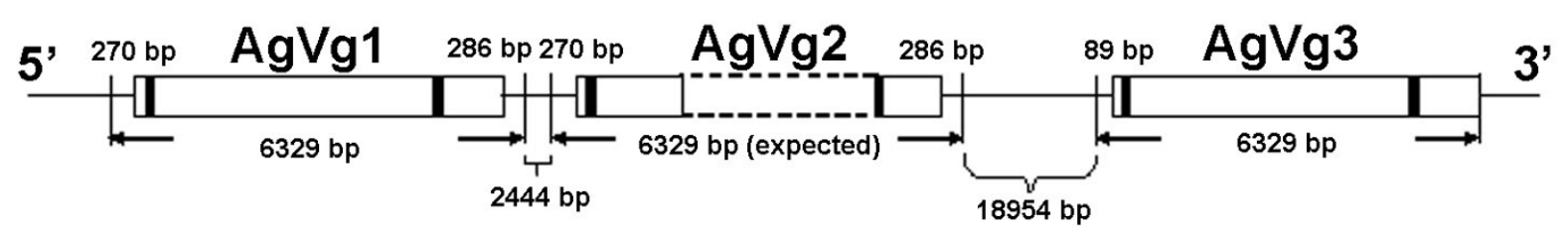

Figure 1 The organization of Anopheles gambiae vitellogenin genes. The tandem repeat organization was generated by the combination of two available sequences from GenBank (Access numbers AAAB01008880 and AF281078). The thin solid lines represented 5'end and 3'end regions, open boxes represent coding sequences, and the filled boxes represent intron sequences. The dashed lines indicate the unavailable data from whole genome sequence. The sizes of the intergenic regions are indicated by brackets (not to scale). Numbers above the sequences indicate the length in base pairs of the corresponding sequence.

functional protein-protein binding domains - a RINGfinger domain and MATH domain (Figure 2a) and has homology to the human tripartite motif protein 37 (TRIM37) gene - we therefore refer to this gene as TRIM37-like (T37L) protein. By examining Vtg gene sequence data from other mosquitoes (Cx. pipiens, Ae. aegypti, Ae. polynesiensis, An. gambiae and Oc. triseriatus) we identified T37L homologues upstream of one of the Vtg copies in all species examined (Figure 2). Among mosquitoes, the size of the intergenic region ranged from 769 bp to $1004 \mathrm{bp}$ (Figure 2). The T37L amino acid sequences were highly conserved among mosquito species (Figure 2). RT-PCR showed that in Cx. tarsalis CtT37L was transcriptionally expressed in all developmental stages (Figure 2). Interestingly, the down-stream associated $V t g$ gene $(C t V g 1 b)$ is also expressed in all developmental stages [22]. The discovery of conservation of the T37L-Vtg structure in all examined mosquito genomes indicated the Vtg gene in this special organization was likely the ancestral origin of mosquito $V t g$ genes through gene duplication events.

\section{Identification of orthologues and paralogues between closely-related mosquito species}

To determine the orthologous relationship of the $V t g$ genes from $C x$. pipiens and $C x$. tarsalis, we used their $5^{\prime}$ promoter sequences to calculate identity by BLAST analysis (Table 1). The vertical and horizontal directions in Figure 3 show orthologous and paralogous relationship, respectively. The 5 promoter region of each orthologous gene shared 70.6-85.3\% nucleotide identity, while producing no significant match with any other Vtg gene (Figure 3). For example, CtVg1a shared $81.1 \%$ nucleotide identity with $C p V g 1 a$ in their $1.1 \mathrm{~Kb} 5$ promoter region directly upstream of the start codon, but no significant match alignment with that region from the other $V t g$ genes.

\section{Phylogenetic analysis}

Phylogenetic analysis using the full Vtg coding sequences was used to examine the evolution of Vtg genes among mosquitoes (Figure 4). All analyses gave identical tree morphology. With the exception of the Culex Vg2 group (which represents a duplication event unique to the genus Culex), all other mosquito $\mathrm{Vtg}$ genes conformed to three major clades: Aedes/Ochlerotatus, Culex and Anopheles. The Aedes/Ochlerotatus clade is more closely related to the Culex Vg1 clade than the Anopheles clade, which is in agreement with the agreed relationships of these genera. Paralogous copies cluster more closely than orthologues within each clade. Three independent duplication patterns were observed among mosquito genera. In Culex, a divergent duplication event produced the $V g 1$ and $V g 2$ genes, which each then underwent additional independent duplications generating four $V t g$ genes in total. These duplication events occurred prior to the divergence of pipiens and tarsalis within the genus. The absence of $\mathrm{Vg} 2$ homologues in non-Culex genera may reflect a unique duplication event in Culex, or less likely, independent gene loss events in Anopheles and Aedes/ Ochlerotatus. In Aedes, the early duplication from the ancestral copy generated the $V g A / B$ lineage, which underwent an additional duplication to generate $3 \mathrm{Vtg}$ copies these duplication events occurred prior to the divergence of the Aedes and Ochlerotatus genera. In Anopheles, Vtg gene duplication events occurred rapidly during tandem repeat generation (Figure 4). Unlike Culex and Aedes/ Ochlerotatus, none of the An. gambiae Vtg genes cluster with other members of the genus, suggesting that the rapid tandem repeat generation occurred after the split of gambiae from the other members of the Anopheles genus.

\section{Concerted evolution between mosquito Culex gene paralogues $\mathrm{Vg} 1 \mathrm{a}$ and $\mathrm{Vg} 1 \mathrm{~b}$}

Concerted evolution occurs in multigene families and is expected to generate a higher sequence similarity between paralogues than between orthologues. Statistically significant fragments were identified in paralogues $V g 1 a$ and $V g 1 b$ in the genus Culex. The predicted conversion fragments include not only coding regions but also non coding DNA such as 5 ' promoter regions and introns (Table 2). 


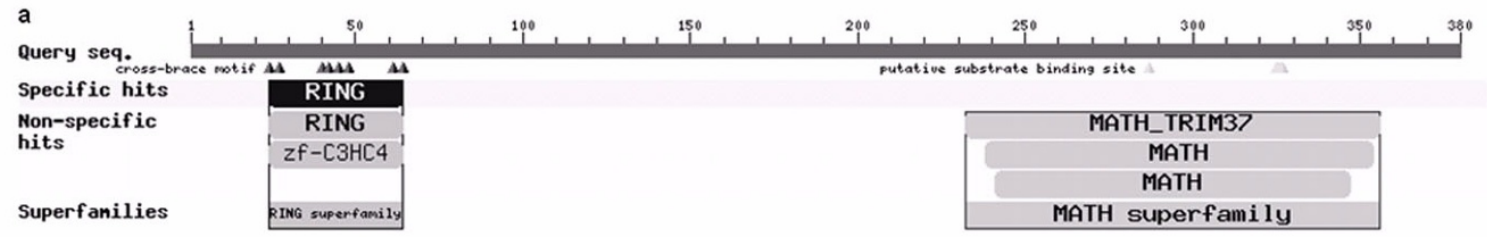

b

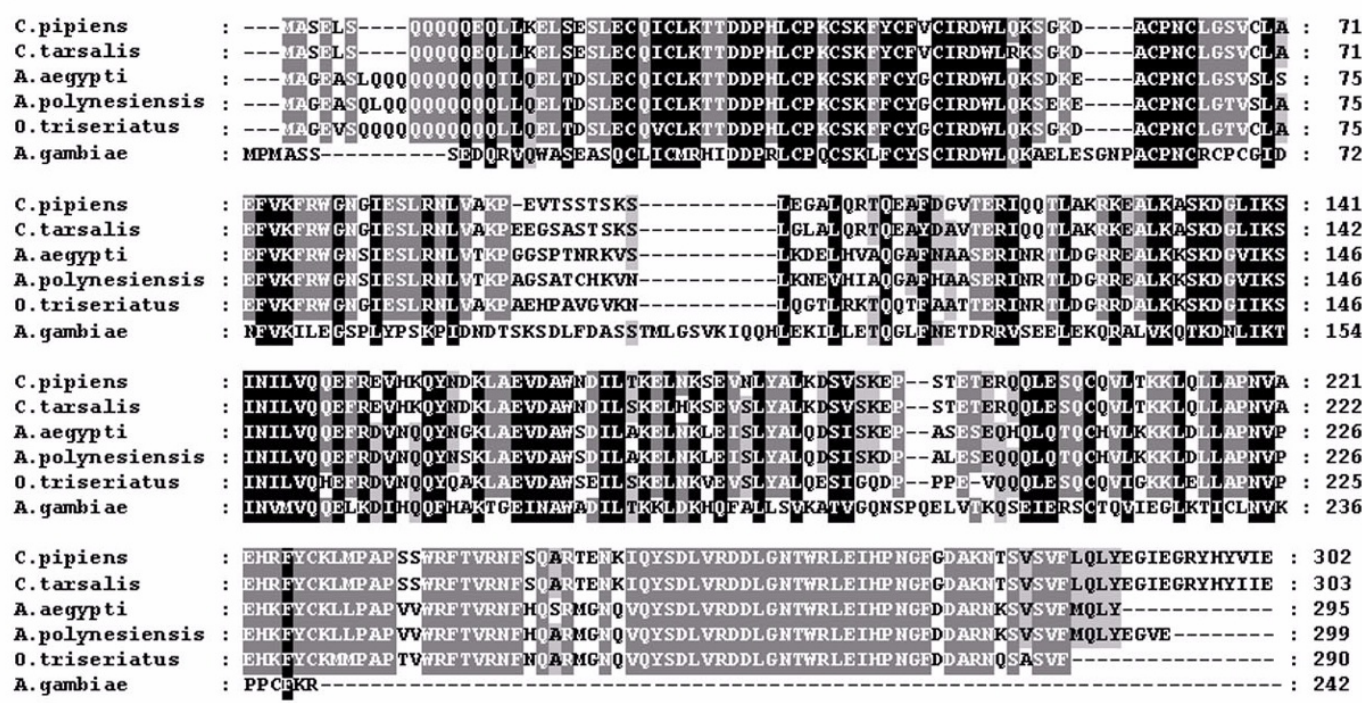

Culex tarsalis

Culexpipiens

Aedes aegypti

Aedespolynesiensis

Ochlerotatustriseriatus

Anophelesgambiae

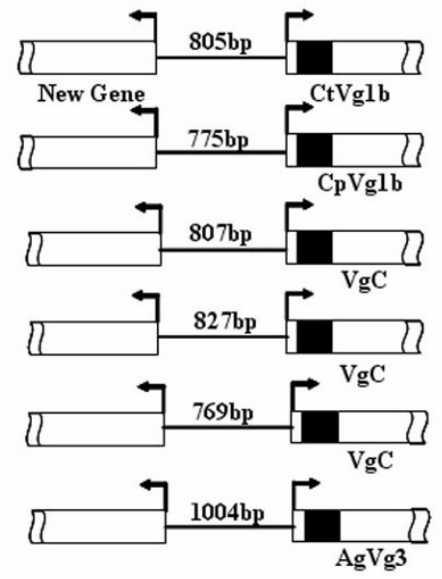

d

$\begin{array}{llllllllllll}\mathrm{L} & 1 & 2 & 3 & 4 & 5 & 6 & 7 & 8 & 9 & 10 & 11\end{array}$

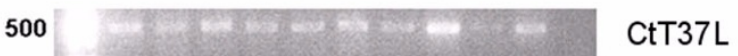

200

L. Ladder $\quad 6$. Female adult $24 \mathrm{~h}$

1. 1 st instar larvae 7. Female adult $48 \mathrm{~h}$

2. $4^{\text {th }}$ instar larvae 8 . Female adult $72 \mathrm{~h}$

3. Male pupae $\quad 9$. Female adult $96 \mathrm{~h}$

4. Female pupae 10. Female adult $120 \mathrm{~h}$

5. Male adult 11. Negative control

Figure 2 The identified novel gene T37L in mosquitoes. (a) T37L protein contains two putative functional protein-protein binding domains: RINGfinger domain and MATH domain. (b). Partial amino acid alignment of T37L genes in six mosquito species. (c) Conservative "tail-to-tail" organization between the T37L and a Vtg gene in mosquitoes. The open boxes represent coding sequence and the filled box represents intron sequence. The intergenic region sizes are indicated. (d) Transcriptional expression of T37 L in Culex tarsalis. Accession numbers are: Culex pipiens, NZ AAWU01017726; Aedes aegypti, AY373377; Aedes polynesiensis, AY691320; Ochlerotatus triseriatus, AY691323; Anopheles gambiae, AAAB01008880.

Though concerted evolution certainly plays an important role in maintaining the high level of mosquito $\mathrm{Vtg}$ gene sequence conservation, an alternative explanation for high sequence homogeneity is "birth and death" evolution under strong purifying selection [23-25]]. The two models of evolution could be distinguished by comparing the number of synonymous differences per site (Ps) within and between species. In the presence of strong purifying selection without concerted evolution, DNA sequence differences will be observed primarily at the 


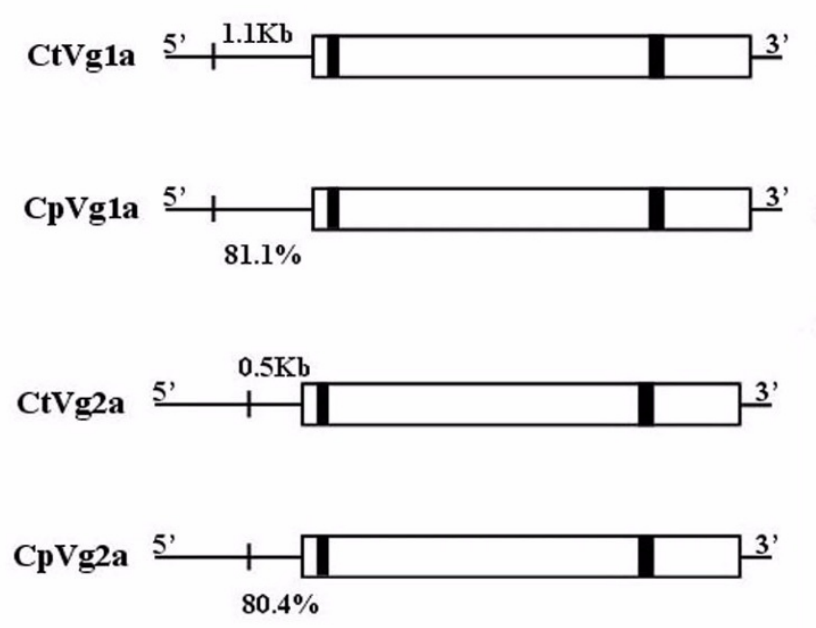

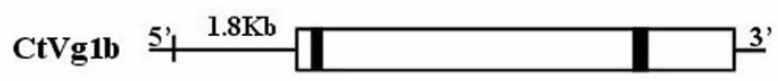
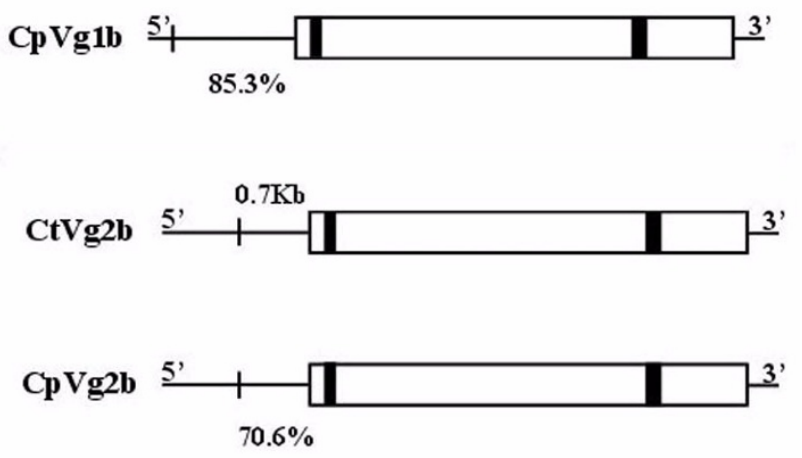

Figure 3 Orthologous/paralogous relationship of Vtg genes in Cx. tarsalis and Cx pipiens. Orthologous and paralogous gene relationships were determined by nucleotide identity of their 5 'promoter regions. The thin solid lines represent 5 'promoter and 3 'end regions, open boxes represent coding sequences, and the filled box represents intron sequence. Sequence direction ( $5^{\prime}$ and $3^{\prime}$ ) and the number of nucleotides with high identity between orthologs in their 5 ' promoter region are indicated above the sequences; the percentage of nucleotide identity is listed below the sequence.

synonymous sites. If a gene has undergone concerted evolution, sequence differences will not be biased toward synonymous sites. If strong purifying selection is responsible for the observed pattern, intraspecific and interspecific synonymous differences are expected to be similar. If intraspecific synonymous differences are much lower than interspecific difference, this would suggest that concerted evolution is the dominant force. In our dataset, Ps values in some paralogous pairs are much lower than that in orthologous pairs. For example, Ps values ranged from 0.0316 to 0.0525 in the paralogous pairs CtVg1a-CtVg1b and $C p V g 1 a-C p V g 1 b$, but ranged from 0.1809 to 0.1851 in the orthologous combinations (Table 3). The Ps value range of 0.0316 to 0.0525 was far from saturation level (0.4-0.7 in many species) [23]. Moreover, extremely high sequence conservation was observed between paralogous introns ( $88.5 \%$ to $100 \%)$, but was lower between orthologous introns $(63.3 \%$ to $81.5 \%)$ in Culex (Table 1) which may not be explained simply by purifying selection. Taken together, the data demonstrated that strong purifying selection is likely not responsible for high sequence identity between gene paralogues within the same family.

\section{Purifying selection between families $\mathrm{Vg} 1$ and $\mathrm{Vg} 2$ in genus Culex}

To examine the selection pressure between the two paralogous families $V g 1$ and $V g 2$ in Culex species, dN/dS values were calculated between $V g 1$ and $V g 2$. All pairwise comparisons were significantly less than 1 ( $\mathrm{p}<0.0001$, Ztest), indicating that these Vtg sequences are under purifying selection (Table 4). No significant conversion tracts were detected using GENECONV (data not shown). To test if positive selection was acting on different regions of mosquito Vtg genes, we used WSPMaker http://wspmaker.kobic.kr/, a web tool for scanning and calculating selection pressures in sub-regions of two protein-coding DNA sequences [26]. No dN/dS ratio was significantly greater than 1 (data not shown).

\section{Mosaic evolution between paralogues $\mathrm{Vg} 2 \mathrm{a}$ and $\mathrm{Vg} 2 \mathrm{~b}$ in Culex, and paralogues in An. gambiae, Ae. aegypti and Oc. atropalpus}

We observed that gene conversion events were variable in the amount of gene sequence involved between mosquito species. While in some species, almost the entire gene sequences have undergone concerted evolution, others had a mosaic pattern of conversion events, where some segments of the genes are homogenized and evolved in concert, while others diverged without gene conversion [27]. We determined that sequence homogenization by gene conversion occurred in the entire gene sequences of Culex Vg1 paralogues, while homogenization occurred only partially in Culex $\mathrm{Vg} 2$ paralogues, An. gambiae paralogues, Ae. aegypti paralogues and Oc. atropalpus paralogues (Table 2). The lower number of synonymous differences per site (Ps) found in paralogues of $C p V g 2 a$ $C p V g 2 b, C t V g 2 a-C t V g 2 b$ and $A g V g 1-A g V g 3$ (ranging from 0.0226-0.0564), suggests that sequence homogenization was not due to strong purifying selection (Table 3). We analyzed $\mathrm{dN} / \mathrm{dS}$ ratios between the unconverted coding region of the paralogues $V g 2 a$ and $V g 2 b$ in Culex, and paralogues in An. gambiae, Ae. aegypti and Oc. atropal- 


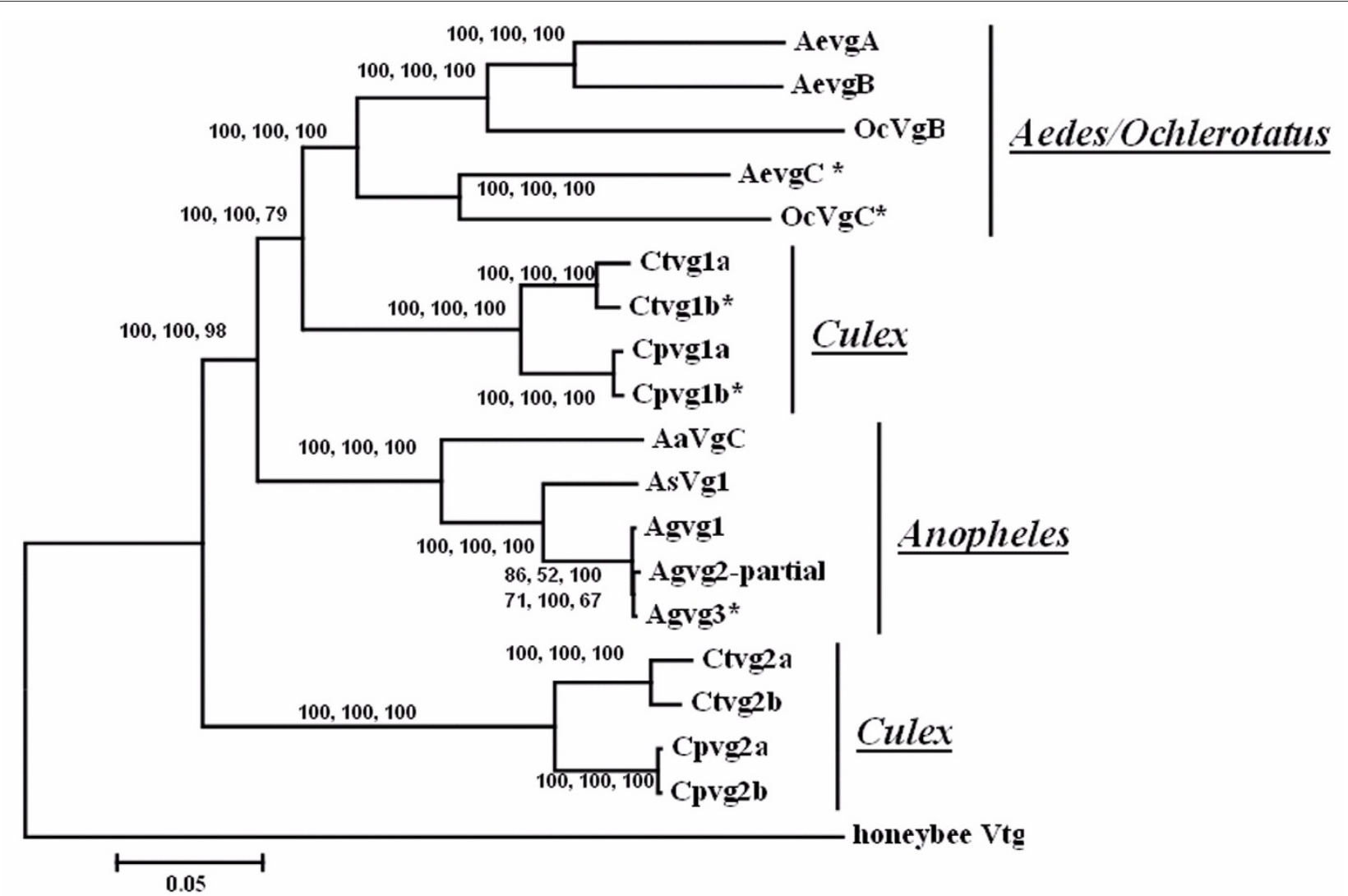

Figure 4 Phylogenetic analysis of mosquito Vtg genes. Phylogenetic analysis of mosquito vitellogenin gene sequences was conducted using Maximum Likelihood, Bayesian and Neighbor-joining methods; numbers at nodes indicate support values for each method (in that order). T37L-associated (putative ancestral) Vtg copies in different mosquito species are indicated by "*". Vtg gene of honey bee Apis mellifera (accession number AJ517411) was used as outgroup. Vtg gene accession numbers are AJ517411 for honey bee, AY691327 for AaVgC and the remainder are listed in Table 2.

pus. All unconverted coding regions have likely undergone purifying selection $(\mathrm{dN} / \mathrm{dS}<1, \mathrm{p}<0.01$, Z-test) (Table 5).

\section{Discussion}

T37L was accidentally identified during attempts to isolate the 5-prime regulatory region of the $C x$. tarsalis $\mathrm{Vg} 1 \mathrm{~b}$ gene. We found that T37L was constitutively expressed throughout mosquito immature and adult development. Interestingly, of the four $V t g$ genes in Cx. tarsalis, $V g 1 b$ is also constitutively expressed throughout immature and mature development, mirroring the expression of T37L [22]. The fact that this gene arrangement (T37L-short regulatory region- $V t g$ ) is conserved among mosquitoes suggests that their functions may be linked in some way. Experiments are currently ongoing to investigate the potential functional link between T37L and Vtg expression, possibly mediated by the shared putatively bi-directional promoter.

GENECONV is a computational program for statistically detecting high-scoring aligned pairs in a given align- ment [28]. It potentially detects both gene conversion and unequal recombination events (two mechanisms to generate concerted evolution) but can not distinguish between the two phenomena. Gene conversion is an event in DNA genetic recombination, where all or part of one gene is converted to the sequence of a nearby homologous gene in a nonreciprocal transfer of genetic information [29]. Gene conversion is used to explain concerted evolution between duplicated genes (two copies) without changing copy number [30,31]. Unequal crossover is a recombination event between misaligned non-allelic sequences on a pair of homologous chromosomes and usually causes copy-number fluctuation by deletion or duplication of the gene region [29]. It is often used to explain concerted evolution within tandemlyarrayed gene families (three or more copies) and always generates duplicates in the same orientation ("head-totail"). There is no tandem repeat of $V t g$ genes found in the genomes of genus Culex, Aedes or Ochlerotatus, suggesting that gene conversion rather than unequal crossover generated the concerted evolution of Vtg genes in these 
Table 2: Detection of gene conversion events in mosquito vitellogenin genes by GENECONV\#, showing the length and location of the converted genomic regions.

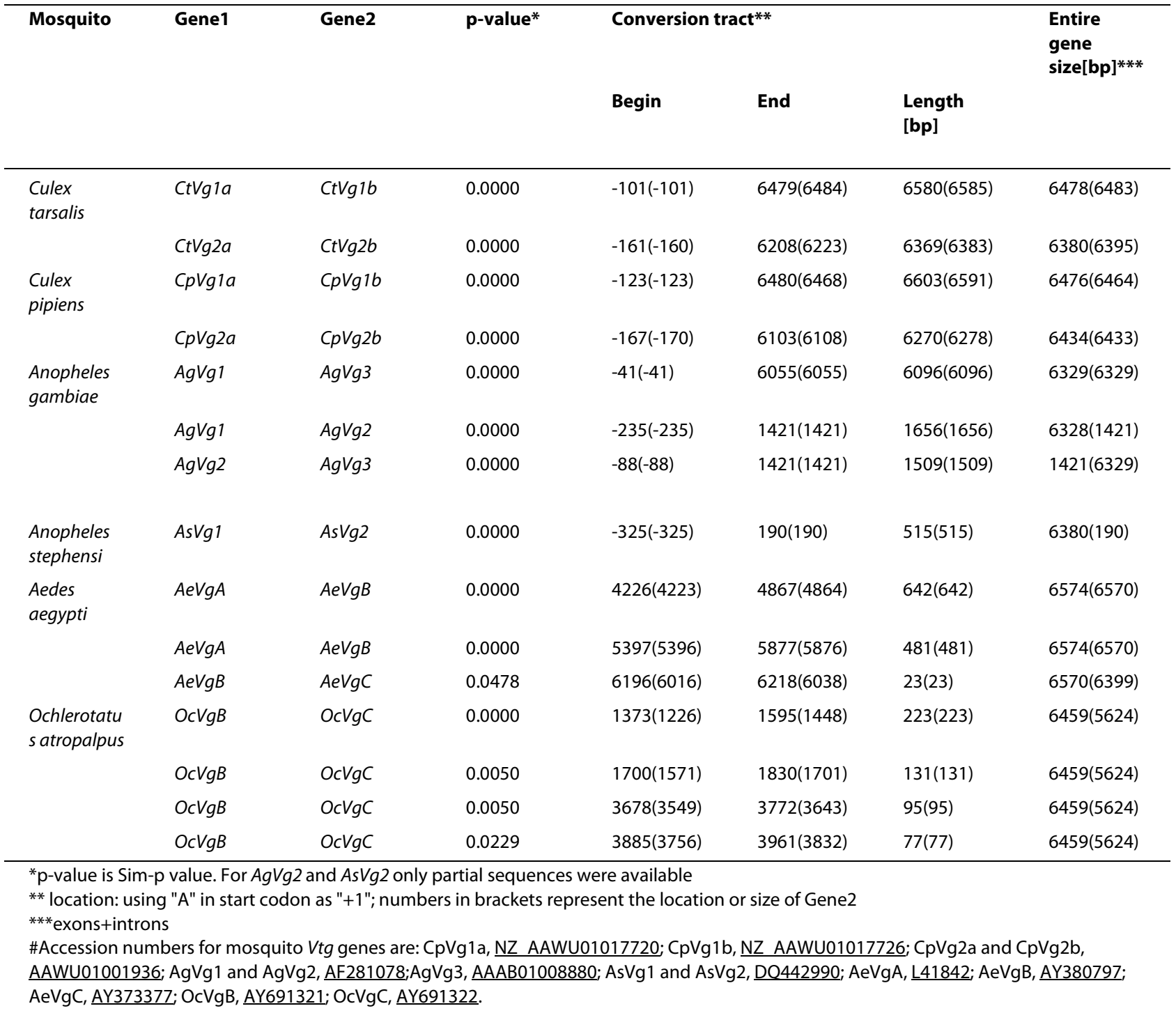

mosquito species. In contrast, in An. gambiae unequal crossover may contribute the concerted evolution of $\mathrm{Vtg}$ genes due to the tandem repeat organization ("head-totail") of the Vtg genes that share high sequence conservation. Different numbers of $V t g$ tandem copies have been described between different mosquito strains (An. gambiae G3 strain: 3 copies vs. PEST strain: 7 copies [32], suggesting unequal crossover may generate $V t g$ copy number fluctuations in Anopheles.

In this study, we determined that after arising by duplication events, purifying selection and concerted evolution drive the evolution of mosquito Vtg genes. Similar patterns have been observed in the Vtg genes of other invertebrate and vertebrate organisms. Among the six Vtg genes (Vit-1 to Vit-6) of the nematode Caenorhabditis elegans, high sequence identity was observed between Vit-1 and Vit-2 (95\% nt identity) and among Vit-3, Vit-4 and Vit-5 (above 96\%), while Vit-3 and Vit-4 are located in tandem on the $\mathrm{X}$ chromosome and are nearly identical to each other in the coding region [33]. Two Vtg genes located at different loci were identified from the cockroach Leucophaea maderae which shared high similarity (96\% identity at the amino acids level) [34]. In vertebrates, four $V t g$ genes have been identified from the frog Xenopus laevis which fall into two pairs that share approximately $95 \%$ sequence identity within pairs, while approximately $65.5 \%$ identity between pairs [1]. A genomic region harboring two $\mathrm{Vtg}$ genes that shared almost $99 \%$ sequence identity and that were separated from each other by a 4.5-kb intergenic region was isolated 
Table 3: Numbers of synonymous $P_{S}(S E)$ and nonsynonymous $P_{N}(S E)$ differences per site in mosquito Vtg genes.

\begin{tabular}{|c|c|c|c|c|}
\hline & Gene1 & Gene2 & PS(SE) & PN(SE) \\
\hline \multirow[t]{8}{*}{ Orthologues } & Ctvg1a & Cpvgla & $0.1851(0.0097)$ & $0.0457(0.0036)$ \\
\hline & $C t V g 1 b$ & $C p V g 1 b$ & $0.1809(0.0093)$ & $0.0432(0.0034)$ \\
\hline & Ctvg2a & Cpvg2a & $0.2377(0.0102)$ & $0.0514(0.0038)$ \\
\hline & Ctvg2b & Cpvg2b & $0.2277(0.0105)$ & $0.0513(0.0039)$ \\
\hline & $A g V g 1$ & AsVg1 & $0.2015(0.0092)$ & $0.0276(0.0029)$ \\
\hline & $A g V g 3$ & AsVg1 & $0.2020(0.0095)$ & $0.0302(0.0031)$ \\
\hline & $A e V g B$ & $O c V g B$ & $0.4881(0.0134)$ & $0.1208(0.0062)$ \\
\hline & $\mathrm{AeVgC}$ & OcVgC & $0.4872(0.0142)$ & $0.2535(0.0093)$ \\
\hline \multicolumn{5}{|l|}{ Paralogues } \\
\hline \multirow[t]{6}{*}{ Culex tarsalis } & CtVgla & $C t V g 1 b$ & $0.0525(0.0054)$ & $0.0047(0.0011)$ \\
\hline & CtVgla & $\mathrm{CtVg} 2 a$ & $0.4941(0.0114)$ & $0.3246(0.0088)$ \\
\hline & CtVgla & $C t V g 2 b$ & $0.4936(0.0116)$ & $0.3232(0.0089)$ \\
\hline & $C t V g 1 b$ & CtVg2a & $0.4909(0.0117)$ & $0.3226(0.0087)$ \\
\hline & $C t V g 1 b$ & $C t V g 2 b$ & $0.4930(0.0120)$ & $0.3216(0.0088)$ \\
\hline & $\mathrm{CtVg} 2 a$ & $C t V g 2 b$ & $0.0564(0.0052)$ & $0.0136(0.0019)$ \\
\hline \multirow[t]{6}{*}{ Culex pipiens } & CpVg1a & $C p V g 1 b$ & $0.0316(0.0039)$ & $0.0033(0.0010)$ \\
\hline & CpVg1a & $C p V g 2 a$ & $0.4708(0.0116)$ & $0.3233(0.0093)$ \\
\hline & CpVg1a & $C p V g 2 b$ & $0.4689(0.0120)$ & $0.3236(0.0094)$ \\
\hline & $C p V g 1 b$ & $C p V g 2 a$ & $0.4658(0.0119)$ & $0.3231(0.0094)$ \\
\hline & $C p V g 1 b$ & $C p V g 2 b$ & $0.4640(0.0122)$ & $0.3234(0.0095)$ \\
\hline & $C p V g 2 a$ & $C p V g 2 b$ & $0.0334(0.0037)$ & $0.0087(0.0017)$ \\
\hline Anopheles gambiae* & $A g V g 1$ & $A g V g 3$ & $0.0226(0.0031)$ & $0.0072(0.0013)$ \\
\hline \multirow[t]{3}{*}{ Aedes aegypti** } & $A e V g A$ & $A e V g B$ & $0.3294(0.0118)$ & $0.0663(0.0045)$ \\
\hline & $A e V g A$ & $\mathrm{AeVgC}$ & $0.4758(0.0119)$ & $0.2488(0.0072)$ \\
\hline & $A e V g B$ & $\mathrm{AeVgC}$ & $0.4839(0.0126)$ & $0.2461(0.0075)$ \\
\hline $\begin{array}{l}\text { Ochlerotatus } \\
\text { atropalpus }\end{array}$ & $O c V g B$ & OcVgC & $0.5283(0.0121)$ & $0.2563(0.0087)$ \\
\hline
\end{tabular}

${ }^{*} A g V g 2$ not used for calculation due to partial available sequence

**Ps value for AeVgA-AeVgB two conversion tracts (648 bp, $496 \mathrm{bp}$ ) are 0.1958(0.0286) and 0.0283 (0.0137)

from the rainbow trout Oncorhynchus mykiss [35]. O. mykiss also contains a locus containing twenty complete $V t g$ genes and ten pseudogenes per haploid genome that show a high degree of similarity at the sequence level (97.4\%-100\%), although these genes differ from each other by retrotransposon-like sequence insertions, deletions and rearrangement events [36]. Other salmonid fishes show a similar pattern [37]. Gene conversion has been suggested as one of the forces driving evolution of some fish Vtg genes [38], but has not been systematically examined across diverse taxa. Re-analysis of sequence data from vertebrates and invertebrates show that concerted evolution and/or purifying selection may be a general property of $V t g$ gene evolution across highly divergent taxa [additional file 1, 2]. However, other evolutionary forces can also drive the evolution of $V t g$ genes. For example, a tandemly-arrayed $V t g$ gene cluster (VGC) has been selectively conserved in most oviparous vertebrate lineages $[39,40]$.

Although both purifying selection and concerted evolution play important roles in maintaining high levels of sequence conservation, they act by different methods. A gene under purifying selection can maintain sequence conservation in protein coding or regulatory regions due to the functional constraint of selection pressure against deleterious variants. Concerted evolution is a molecular process that leads to homogenization of DNA sequences of duplicated regions within a genome. In yeast, it has 
Table 4: $\mathrm{dN} / \mathrm{dS}$ ratios and evidence for purifying selection between two paralogous families $\mathrm{Vg} 1$ and $\mathrm{Vg} 2$ in Culex.

\begin{tabular}{|c|c|c|c|c|}
\hline mosquito & $V g 1$ & Vg2 & $\mathrm{dN} / \mathrm{dS}$ & p-value (Z-test) \\
\hline \multirow[t]{4}{*}{ Culex pipiens } & $C p V g 1 a$ & $C p V g 2 a$ & 0.5726 & 0.0000 \\
\hline & $C p V g 1 a$ & $C p V g 2 b$ & 0.5792 & 0.0000 \\
\hline & $C p V g 1 b$ & CpVg2a & 0.5824 & 0.0000 \\
\hline & CpVg1b & $C p V g 2 b$ & 0.5890 & 0.0000 \\
\hline \multirow[t]{4}{*}{ Culex tarsalis } & CtVgla & $\mathrm{CtVg} 2 a$ & 0.5300 & 0.0000 \\
\hline & CtVgla & $C t V g 2 b$ & 0.5279 & 0.0000 \\
\hline & $C t V g 1 b$ & $\mathrm{CtVg} 2 a$ & 0.5301 & 0.0000 \\
\hline & $C t V g 1 b$ & $C t V g 2 b$ & 0.5246 & 0.0000 \\
\hline
\end{tabular}

been shown that the level of concerted evolution is positively correlated with gene expression levels, suggesting that dosage-sensitive genes are likely to favor concerted evolution [41]. Vtg is an essential component needed for embryonic development. Increased quantities of egg yolk may have dramatically beneficial effects on embryo survival. The high identity of $\mathrm{Vtg}$ genes maintained by concerted evolution may be beneficial for mosquito reproduction due to increased expression of this vital yolk protein.

After duplication, the duplicated gene copy can have different fates, such as loss of function through pseudogene formation or diversification of gene function through neofunctionalization [42,43]. It has been reported that Vtg gene vit-1 in C. elegans and about ten $V t g$ genes in rainbow trout were actually pseudogenes $[33,36]$. In Cx. tarsalis, all of four Vtg genes are transcriptionally expressed and are not pseudogenes [22]. Vtg genes may also gain novel functions through alteration of their transcriptional expression pattern instead of sequence divergence. In the honeybee, $V t g$ is expressed in immature, worker and male castes and is associated with a variety of social behaviours [44-46]. Vtg proteins also have important antioxidant activities and prolong lifespan in honey bee and C. elegans $[47,48]$. Vtg is also involved in promoting macrophage phagocytosis in fish [49]. In Cx. tarsalis, CtVg1b is expressed not only in the adult female but is constitutively expressed during larval and pupal developmental stages, while CtVg1a, CtVg2a and $C t V g 2 b$ are expressed exclusively in the adult stage[22] - it remains to be seen if $C t V g 1 b$ has any alternative function in $C x$. tarsalis and whether constitutive expression is related to the associated $C t T 37 \mathrm{~L}$ gene.

\section{Conclusions}

After duplication, two major forces drive the evolution of the vitellogenin $(V t g)$ gene family in mosquitoes. We identified the putative ancestral $\mathrm{Vtg}$ gene among different mosquito species by its conserved association with a novel gene (T37L) approximately one kilobase upstream of the start codon. Phylogenetic analysis indicated that the $V t g$ gene family arose by unique duplication events in each mosquito genera. Signatures of purifying selection were detected in Culex, Aedes and Anopheles. Gene conversion is a major driver of concerted evolution in Culex, while unequal crossover is likely the major driver of concerted evolution in Anopheles. In Aedes, smaller fragments have undergone gene conversion events. These data, plus reanalysis of $\mathrm{Vtg}$ gene sequences from other organisms suggest that duplication, concerted evolution and purifying selection may be major evolutionary forces driving $V t g$ gene evolution across highly divergent taxa.

\section{Methods \\ Mosquitoes}

Culex tarsalis were from the KNWR strain, which was collected in the Kern National Wildlife Refuge (KNWR) in Kern County, California. Larvae were reared at a standard density of 200 larvae/pan and fed a 1:2:2 blend of fish food, rabbit pellets and bovine liver extract. Adults were maintained on $10 \%$ sucrose. Mosquitoes were maintained by autogenous oviposition.

\section{Genomic DNA extraction, total RNA extraction and first strand CDNA synthesis}

Genomic DNA was isolated from $C x$. tarsalis adults using the procedure described in Chen and Li [50]. Total 
Table 5: Purifying selection on unconverted coding region of mosquito Vtg genes.

\begin{tabular}{|c|c|c|c|c|c|c|c|c|}
\hline mosquito & Gene1 & Gene2 & $\begin{array}{l}\text { Size of non- } \\
\text { converted } \\
\text { region[bp]† }\end{array}$ & PS & $\mathrm{dN}$ & dS & $d N / d S$ & p-value (Z-test) \\
\hline Culex pipiens & $C p V g 2 a$ & $C p V g 2 b$ & $331(331)$ & 0.5314 & 0.1772 & 0.9246 & 0.1917 & 0.0003 \\
\hline Culex tarsalis & $C t V g 2 a$ & $C p V g 2 b$ & $172(172)$ & 0.5887 & 0.3456 & 1.1524 & 0.2999 & 0.0191 \\
\hline $\begin{array}{l}\text { Anopheles } \\
\text { gambiae }\end{array}$ & $A g V g 1$ & $A g V g 3$ & $274(274)$ & 0.3868 & 0.1344 & 0.5439 & 0.2471 & 0.0002 \\
\hline \multicolumn{9}{|l|}{ Aedes aegypti } \\
\hline Fragment1 & $A e V g A$ & $A e V g B$ & 4329(4314) & 0.3548 & 0.0706 & 0.4805 & 0.1469 & 0.0000 \\
\hline Fragment2 & $A e V g A$ & $A e V g B$ & $472(472)$ & 0.2920 & 0.1053 & 0.3700 & 0.2846 & 0.0001 \\
\hline Fragment3 & $A e V g A$ & $A e V g B$ & $697(694)$ & 0.3852 & 0.1109 & 0.5405 & 0.2052 & 0.0000 \\
\hline Fragment1 & $A e V g B$ & $\mathrm{AeVgC}$ & $6055(5881)$ & 0.4960 & 0.2876 & 0.8121 & 0.3454 & 0.0000 \\
\hline Fragment2 & $A e V g B$ & $\mathrm{AeVgC}$ & $352(361)$ & 0.3089 & 0.4010 & 0.3981 & 1.0073 & $1.0000^{*}$ \\
\hline $\begin{array}{l}\text { Fragment1-2 } \\
\text { (combined) }\end{array}$ & $A e V g B$ & $\mathrm{AeVgC}$ & & 0.4870 & 0.2942 & 0.7860 & 0.3743 & 0.0000 \\
\hline \multicolumn{9}{|l|}{$\begin{array}{l}\text { Ochlerotatus } \\
\text { atropalpus }\end{array}$} \\
\hline Fragment1 & $O c V g B$ & $\mathrm{OcVgC}$ & $1298(1145)$ & 0.5889 & 0.2581 & 1.1536 & 0.2237 & 0.0000 \\
\hline Fragment2 & $O c V g B$ & $\mathrm{OcVgC}$ & $104(123)$ & 0.6291 & 0.4917 & 1.3687 & 0.3592 & $0.0508^{*}$ \\
\hline Fragment3 & $O c V g B$ & OcVgC & $1847(1847)$ & 0.5320 & 0.2651 & 0.9267 & 0.2861 & 0.0000 \\
\hline Fragment4 & $O c V g B$ & $\mathrm{OcVgC}$ & $112(112)$ & 0.6267 & 0.3979 & 1.3541 & 0.2938 & $0.0569^{*}$ \\
\hline Fragment5 & $O c V g B$ & OcVgC & $2437(1724)$ & 0.4952 & 0.4549 & 0.8096 & 0.5619 & 0.0000 \\
\hline $\begin{array}{l}\text { Fragment } 1-5 \\
\text { (combined) }\end{array}$ & $O c V g B$ & $\mathrm{OcVgC}$ & & 0.5369 & 0.3306 & 0.9436 & 0.3504 & 0.0000 \\
\hline
\end{tabular}

*no significant selection pressure on these fragments

†Size Gene 1(Size Gene 2)

RNA was extracted from female adults using the SV Total RNA Isolation System Kit (Promega) as described by the manufacturer. Two micrograms of RNA was used as template for first strand cDNA synthesis to make 3'RACEready cDNA using The SMART RACE cDNA Amplification Kit according to the manufacturer's protocol (Clonetech).

\section{Cloning full length vitellogenin genes from Culex tarsalis}

To isolate the full Vtg coding sequences, we began by cloning partial coding sequences. Based on the available An. gambiae, Ae. aegypti and Cx. pipiens vitellogenin sequences, two primers (CpVgCoF1: 5'-CCA-AGA-CCATGA-CCG-CCC-TG-3' and CpVgCoR1: 5'-TTT-CCCATT-TGG-TTG-GTG-TTG-GG-3') were designed to PCR-amplify the coding sequence near the $5^{\prime}$ end. The PCR protocol was 2 min at $94^{\circ} \mathrm{C}$, followed by 35 cycles consisting of $94^{\circ} \mathrm{C}$ for $30 \mathrm{~s}, 50^{\circ} \mathrm{C}$ for $30 \mathrm{~s}$, and $72^{\circ} \mathrm{C}$ for 1 min, and a final $72^{\circ} \mathrm{C}$ extension for $10 \mathrm{~min}$. PCR products were separated on a $1 \%$ agarose gel in $1 \times$ TAE buffer. PCR fragments were cloned into the TOPO TA cloning vector (Invitrogen) and sequenced. Two partial vitellogenin gene ( $V g 1$ and $V g 2)$ sequences were identified.

The 5'-flanking sequences were obtained using the GenomeWalker Universal Kit (Clonetech) according to the manufacturer's protocol. Briefly, genomic DNA was digested by eight blunt-end restriction enzymes (SnaBI, MscI, SmaI, ScaI, EcorV, Dra, PvuII, Stu I), and then adaptor-ligated on both ends. Use adaptor and gene-specific primers, we amplified the 5 flanking regions. Two gene-specific primers were designed for each gene. $\mathrm{Vg} 1$ : Vg1GSP1 (5'-CTC-CCT-CCA-GAT-GTT-GGT-ACGGTA-TCC-3') and Vg1GSP2 (5'-TCG-TTG-AAG-TTGGCG-TAC-TCG-GCT-TGC-3'); Vg2: Vg2GSP1 (5'-AAGTCC-GTG-CGG-TGA-CCA-TCG-TCC-AGA-3'); Vg2GSP2 (5'-ATA-CTG-GTT-GAA-CTG-AGC-GTATTG-AGC-3'). The nested PCR protocol was $2 \mathrm{~min}$ at 
$94^{\circ} \mathrm{C}$, followed by 20 cycles consisting of $94^{\circ} \mathrm{C}$ for $30 \mathrm{~s}$, $67^{\circ} \mathrm{C}$ for $4 \mathrm{~min}$, and a final $72^{\circ} \mathrm{C}$ extension for $10 \mathrm{~min}$; the second PCR reaction was identical except that cycles were increased to 30 and used $1 \mu \mathrm{l} 50 \times$ dilution of the first PCR product as template. A 10:1 mix of Taq and pfu DNA polymerase was used for all reactions. PCR fragments were TOPO cloned and sequenced as described above.

3'Rapid Amplification of cDNA ends (3'RACE) approach was used to isolate the $3^{\prime}$ end of the Vtg genes. Two forward gene-specific primers were designed for each Vtg gene for nested 3'RACE PCR on the basis of 3' coding sequence of the $C x$. pipiens Vtg genes. Vg1: CpVg13F1 (5'-ACT-TCC-AGA-ACG-CTG-ACA-CC-3') and CpVg13F2 (5'-TCA-AGA-ACG-GAT-TCA-GCGAG-3'); Vg2: CpVg23F1 (5'-GAG-AAC-AAC-CAG-CAGCAC-CT-3') and CpVg23F2 (5'-ATT-GTG-CCG-AACGGT-GCT-CA-3'). The nested PCR protocol was 2 min at $94^{\circ} \mathrm{C}$, followed by 20 cycles consisting of $94^{\circ} \mathrm{C}$ for $30 \mathrm{~s}$, $52^{\circ} \mathrm{C}$ for $30 \mathrm{~s}$ and $72^{\circ} \mathrm{C}$ for $90 \mathrm{~s}$, and a final $72^{\circ} \mathrm{C}$ extension for $10 \mathrm{~min}$; the second $\mathrm{PCR}$ reaction was identical except that cycles were increased to 30 and used $1 \mu \mathrm{l} 50 \times$ diluted PCR product as template. PCR fragments were TOPO cloned and sequenced as described above.

Finally, we designed four pairs of gene-specific primers to amplify the four full length Vtg genes, in which forward primers and reverse primers were located in $5^{\prime}$ promoter region and 3'UTR region, respectively. Vg1a: Vg1aPF (5'-GAA-CCC-ACC-GAT-TGT-TTA-CG-3') and Vg1aSPR (5'-ATG-CCT-TTG-TAA-ACA-GTT-CC-3'); Vg1b: Vg1bPF (5'-TGG-TGT-TGC-TCT-CAG-ACT-TG3') and Vg1bSPR (5'-CCA-AAT-TCA-TTG-CTT-TCCGA-3'); - Vg2a: Vg2aPF (5'-TCA-ACA-ACC-ATC-CCTTCA-CA-3') and Vg2aSPR (5'-TCC-GTT-ACA-ACCATC-TAG-AG-3'); Vg2b: Vg2bPF (5'-AAA-GCA-GCCTCA-AGC-AAT-CG-3') and Vg2bSPR (5'-GGC-AGTTGT-ATC-TTC-CAA-GG-3'). The PCR protocol was 2 min at $94^{\circ} \mathrm{C}$, followed by 35 cycles consisting of $94^{\circ} \mathrm{C}$ for $30 \mathrm{~s}, 50^{\circ} \mathrm{C}$ for $30 \mathrm{~s}$, and $72^{\circ} \mathrm{C}$ for $4 \mathrm{~min} 30 \mathrm{sec}$, and a final $72^{\circ} \mathrm{C}$ extension for $10 \mathrm{~min}$. PCR products were cloned and sequenced as described above. The four new isolated $V t g$ genes from $C x$. tarsalis have been deposited in GenBank under accession numbers GU017909-GU017912.

\section{Temporal expression of the TRIM37-like protein (CtT37L) gene in Cx. tarsalis}

While isolating the 5 -promoter region of the CtVg1b gene, we identified a novel gene (CtT37L - see results) 805 bp upstream of the CtVglb start codon, in the opposite orientation. We determined the expression profile of CtT37L in Cx. tarsalis by reverse transcriptase PCR. Total RNA was isolated using RNAqueous micro-kit columns (Ambion) from first-instar larvae, fourth instar lar- vae, pupae (male and female), 24-hour old male adults, and female adults 24, 48, 72, 96 and 120 hours post-emergence. The experiment was replicated 3 times. RNA was extracted from 5 pooled individuals except in the case of first instar larvae where 10 individuals were pooled. Isolated RNA was treated with DNase (Ambion) to eliminate residual DNA contamination. cDNA was generated using $1 \mu \mathrm{g}$ of DNase-treated RNA for reverse transcription using the Superscript RT for PCR kit (Invitrogen) in $20 \mu \mathrm{l}$ volumes with Oligo(dT)20 primers. No-RT controls were run for each sample. For RT-PCR $2 \mu \mathrm{l}$ of cDNA was used as a template for amplification with following primers (5'3'): CtTF109F: CTT-TTG-GTC-CAC-GAA-GTG-GT; CtTF561R: GCT-TTG-AAG-GAC-AGC-GTT-TC. Control actin primers were: actin1F: ATG-TTT-GAG-ACCTTC-AAC-TCG-C, actin1R: TAA-CCT-TCR-TAG-ATTGGG-ACG. PCR conditions were $94^{\circ} \mathrm{C}$ for $3 \mathrm{~min}$, followed by 30 cycles of: $94^{\circ} \mathrm{C}$ for $30 \mathrm{sec}, 50^{\circ} \mathrm{C}$ for $30 \mathrm{sec}$, $72^{\circ} \mathrm{C}$ for $30 \mathrm{sec}$, followed by a final extension of $72^{\circ} \mathrm{C}$ for $10 \mathrm{~min}$. Amplicons were resolved by agarose gel electrophoresis.

\section{Data mining, sequence analysis and phylogenetic analysis}

The complete Vtg genes were identified by from the available An. gambiae, Ae. aegypti and Cx. pipiens genome sequences, and GENBANK sequence data from Ae. polynesiensis, An. stephensi, An. albimanus and Ochlerotatus atropalpus. Sequence analysis was performed using Blast http://www.ncbi.nlm.nih.gov/blast/ against a non-redundant database. Initial alignments were performed on amino acid sequences using Vector NTI advance 10 (Invitrogen) followed by inference of the nucleotide alignment. Phylogenetic analysis of mosquito Vtg genes was conducted on the amino acid alignment using Maximum Likelihood (ML), Bayesian (B) and neighbour-joining (NJ) algorithms. Bayesian phylogenetic analysis was conducted using MrBayes v 3.1.2 [51]. The WAG model of amino acid substitution was selected as the most appropriate using the MCMC sampler to test all fixed rate matrices. The rate variation over sites followed a gamma distribution with a proportion of invariant sites; these parameters were estimated from the data by MrBayes. Analyses were run for 500,000 generations, sampling every 100 generations. The first $25 \%$ of generated trees were considered the burnin and discarded. We constructed a 50\% majority-rule consensus tree from the remaining trees. Maximum likelihood (ML) phylogenetic analysis was conducted using PHYML [52] with the same parameters estimated for Bayesian analyses. Tree robustness was determined with 100 bootstrap replications. Neighbor-joining analyses were conducted using MEGA v.3.1 [53] with 1000 bootstrap replications. 


\section{Detection of gene conversion events}

$\mathrm{Vtg}$ gene nucleotide alignments were generated as described above. GENECONV was used to detect gene conversion events. Global p-values were calculated based on 1000 permutations of the original data using a BLAST-like search algorithm [28].

\section{Purifying selection tests and Ps,PN calculation}

Analyses were conducted using MEGA v.3.1 [53]. Pairwise $\mathrm{dN} / \mathrm{dS}$ ratios and significance values were calculated using the Nei-Gojobori method with a Jukes-Cantor correction for multiple hits. Standard errors were calculated by 1000 bootstrap replications.

\section{Acknowledgements}

This research was funded by NIH/NIAID grant R01AI067371 to JLR.

\section{Additional material}

\section{Additional file 1 Purifying selection of Vitellogenin genes in addi-} tional vertebrates and invertebrates.

Additional file $\mathbf{2}$ Gene conversion of Vitellogenin genes in additional vertebrates and invertebrates.

\section{Authors' contributions}

SC contributed to study design, carried out molecular experiments, conducted bioinformatic analyses and contributed to drafting the manuscript. JSA contributed to molecular analyses. KNPJ assisted with data analysis and contributed to drafting the manuscript. JMS assisted with data analysis. JLR contributed to study design, assisted with data analysis and contributed to drafting the manuscript. All authors read and approved the final manuscript.

\section{Author Details}

1The W. Harry Feinstone Department of Molecular Microbiology and Immunology, Bloomberg School of Public Health, Johns Hopkins University, Baltimore, MD, 21205, USA, 2The Institute for Genome Sciences, University of Maryland School of Medicine, Baltimore, MD, 21201, USA and ${ }^{3}$ The Johns Hopkins Malaria Research Institute, Bloomberg School of Public Health, Johns Hopkins University, Baltimore, MD, 21205, USA

Received: 11 November 2009 Accepted: 13 May 2010 Published: 13 May 2010

\section{References}

1. Wahli W, Dawid IB, Ryffel GU, Weber R: Vitellogenesis and the vitellogenin gene family. Science 1981, 212:298-304

2. Corthesy B, Leonnard P, Wahli W: Transcriptional potentiation of the vitellogenin BI promoter by a combination of both nucleosome assembly and transcription factors: an in vitro dissection. Mol Cell Biol 1990, 10:3926-3933

3. Koeppe JK, Fuchs M, Chen TT, Hunt LM, Kovalick GE, Briers T: The role of juvenile hormone in reproduction. In Comprehensive Insect Biochemistry and Pharmacology Volume 8. Edited by: Kerkut GA, Gilbert LI. Pergamon Press, Oxford: 1985:165-203.

4. Hagedorn $\mathrm{HH}$ : The role of ecdysteroids in reproduction. In Comprehensive Insect Biochemistry and Pharmacology Volume 8. Edited by: Kerkut GA, Gilbert LI. Pergamon Press, Oxford; 1985:205-262.

5. Raikhel AS, Dhadialla TS: Accumulation of yolk proteins in insect oocytes. Annu Rev Entomol 1992, 37:217-251.

6. Sappington TW, Raikhel AS: Molecular characteristics of insect vitellogenins and vitellogenin receptors. Insect Biochem Mol Biol 1998, 28:277-300

7. Snigirevskaya ES, Raikhel AS: Receptor-mediated endocytosis of yolk proteins in insect oocytes. In Progress in Vitellogenesis. Reproductive
Biology of Invertebrates Volume XII. Issue Part B Edited by: Raikhel AS, Sappington TW. Science Publishers, Inc., Enfield, USA-Plymouth UK; 2005:199-228.

8. Tufail M, Takeda M: Molecular cloning, characterization and regulation of the cockroach vitellogenin receptor during oogenesis. Insect Mol Biol 2005, 14:389-401.

9. Chen JS, Cho WL, Raikhel AS: Mosquito vitellogenin cDNA. Sequence similarity with vertebrate vitellogenin and insect larval hemolymph proteins. J Molec Biol 1994, 237:641-647.

10. Romans $P, T u Z, K e Z$, Hagedorn $\mathrm{HH}$ : Analysis of a vitellogenin gene of the mosquito, Aedes aegypti and comparisons to vitellogenins from other organisms. Insect Biochem Molec Biol 1995, 25:939-958.

11. Kokoza VA, Martin D, Mienaltowski M, Ahmed A, Morton C, Raikhel AS: Transcriptional regulation of the mosquito Aedes aegypti vitellogenin gene by a blood-meal triggered cascade. Gene 2001, 274:47-65.

12. Attardo G, Higgs S, Klingler KA, Vanlandingham DL, Raikhel AS: RNAimediated knockdown of a GATA factor reveals a link to anautogeny in the mosquito, Aedes aegypti. Proc Natl Acad USA 2003, 100:13374-13379.

13. Hansen IA, Attardo GM, Park JH, Peng Q, Raikhel AS: Target of rapamycinmediated amino acid signaling in mosquito anautogeny. Proc Natl Acad Sci USA 2004, 101:10626-10631.

14. Attardo GM, Hansen IA, Raikhel AS: Nutritional regulation of vitellogenesis in mosquitoes: Implications for anautogeny. Insect Biochem Mol Biol 2005, 35:661-675.

15. Park JH, Attardo GM, Hansen IA, Raikhel AS: GATA factor translation is the final downstream step in the amino acid/target-of-rapamycinmediated vitellogenin gene expression in the anautogenous mosquito Aedes aegypti. J Biol Chem 2006, 281:11167-11176.

16. Martin D, Piulachs MD, Raikhel AS: A Novel GATA factor transcriptionally represses yolk protein precursor genes in the mosquito Aedes aegypti via interaction with the CtBP corepressor. Mol Cell Biol 2001, 21:164-174.

17. Kokoza VA, Ahmed A, Cho WL, Jasinskiene N, James AA, Raikhel AS: Engineering blood meal-activated systemic immunity in the yellow fever mosquito, Aedes aegypti. Proc Natl Acad Sci USA 2000, 97:9144-9149.

18. Kokoza VA, Ahmed AS, Wimmer E, Raikhel AS: Efficient transformation of the yellow fever mosquito Aedes aegypti using the pBac[3xP3-EGFP afm] piggy-Bac transposable element vector. Insect Biochem Molec Biol 2001, 31:1137-1143.

19. Nirmala X, Marinotti O, Sandoval JM, Phin S, Gakhar S, Jasinskiene N, James AA: Functional characterization of the promoter of the vitellogenin gene, AsVg1, of the malaria vector, Anopheles stephensi. Insect Biochem Mol Biol 2006, 36:694-700.

20. Chen X, Marinotti O, Whitman L, Jasinskiene N, James AA: The Anopheles gambiae vitellogenin gene (VGT2) promoter directs persistent accumulation of a reporter gene product in transgenic Anopheles stephensi following multiple blood meals. Am J Trop Med Hygiene 2007, 76:1118-1124.

21. Isoe J, Hagedorn HH: Mosquito vitellogenin genes: Comparative sequence analysis, gene duplication, and the role of rare synonymous codon usage in regulating expression. J Insect Sci 2007, 7:1-49.

22. Provost-Javier KN, Chen S, Rasgon JL: Vitellogenin gene expression in autogenous Culex tarsalis. Insect Mol Biol 2010 in press.

23. Nei M, Rogozin IB, Piontkivska H: Purifying selection and birth-anddeath evolution in the ubiquitin gene family. Proc Natl Acad Sci USA 2000, 97:10866-10871.

24. Piontkivska H, Rooney AP, Nei M: Purifying selection and birth-anddeath evolution in the histone $\mathrm{H} 4$ gene family. Mol Biol Evol 2002, 19:689-697.

25. Nei M, Rooney AP: Concerted and birth-and-death evolution of multigene families. Annu Rev Genet 2005, 39:121-152.

26. Lee YS, Kim TH, Kang TW, Chung WH, Shin GS: WSPMaker: a web tool for calculating selection pressure in proteins and domains using windowsliding. BMC Bioinformatics 2008, 9(Suppl 12):S13.

27. Wen Y, Irwin DM: Mosaic evolution of ruminant stomach lysozyme genes. Mol Phylogenet Evol 1999, 13:474-482

28. Sawyer S: Statistical tests for detecting gene conversion. Mol Biol Evol 1989, 6:526-538

29. Chen JM, Cooper DN, Chuzhanova N, Ferec C, Patrinos GP: Gene conversion: mechanisms, evolution and human disease. Nat Rev Genet 2007, 8:762-775 
30. Li WH: Molecular Evolution Sinauer Assocs: Sunderland, MA; 1999.

31. Teshima KM, Innan $\mathrm{H}$ : The effect of gene conversion on the divergence between duplicated genes. Genetics 2004, 166:1553-1560.

32. Romans PA: Unique organization and unexpected expression patterns of A. gambiae Vitellogenin genes. 2005 [http://www.anobase.org/ embo meeting/2005/abstracts/Romans.pdf].

33. Spieth J, Denison K, Kirtland S, Cane J, Blumenthal T: The C. elegans vitellogenin genes: short sequence repeats in the promotor regions and homology to the vertebrate genes. Nucleic Acids Res 1985 13:5283-5295

34. Tufail M, Bembenek J, Elgendy AM, Takeda M: Evidence for two vitellogenin-related genes in Leucophaea maderae: the protein primary structure and its processing. Arch Insect Biochem Physiol 2007, 66:190-203

35. Mouchel N, Trichet V, Naimi BY, Le Pennec JP, Wollf J: Structure of a fish (Oncorhynchus mykiss) vitellogenin gene and its evolutionary implications. Gene 1997, 197:147-152.

36. Trichet V, Buisine N, Mouchel N, Morán P, Pendás AM, Le Pennec JP, Wolff $\mathrm{J}$ : Genomic analysis of the vitellogenin locus in rainbow trout (Oncorhynchus mykiss) reveals a complex history of gene amplification and retroposon activity. Mol Gen Genet 2000, 263:828-37.

37. Buisine $\mathrm{N}$, Trichet $\mathrm{V}$, Wolff $\mathrm{J}$ : Complex evolution of vitellogenin genes in salmonid fishes. Mol Genet Genomics 2002, 268:535-542.

38. Braasch I, Salzburger W: In ovo omnia: diversification by duplication in fish and other vertebrates. J Biol 2009, 8:25.

39. Babin PJ: Conservation of a vitellogenin gene cluster in oviparous vertebrates and identification of its traces in the platypus genome. Gene 2008, 413:76-82

40. Finn RN, Kolarevic J, Kongshaug H, Nilsen F: Evolution and differential expression of a vertebrate vitellogenin gene cluster. BMCEvol Bio/ 2009, 9:2. Forthcoming

41. Sugino RP, Innan $\mathrm{H}$ : Selection for more of the same product as a force to enhance concerted evolution of duplicated genes. Trends Genet 2006, 2:642-644.

42. Prince VE, Pickett FB: Splitting pairs: the diverging fates of duplicated genes. Nat Rev Genet 2002, 3:827-837.

43. Long $M$, Betran $E$, Thornton $K$, Wang W: The origin of new genes: glimpses from the young and old. Nat Rev Genet 2003, 4:865-875.

44. Amdam GV, Norberg K, Fondrk MK, Page RE: Reproductive ground plan may mediate colony-level selection effects on individual foraging behavior in honey bees. Proc Natl Acad Sci USA 2004, 101:11350-11355.

45. Guidugli KR, Nascimento AM, Amdam GV, Barchuk AR, Omholt S, Simoes ZLP, Hartfelder K: Vitellogenin regulates hormonal dynamics in worker caste of a eusocial insect. FEBS Lett 2005, 579:4961-4965.

46. Nelson CM, Ihle KE, Fondrk MK, Page RE, Amdam GV: The vitellogenin gene has multiple coordinating effects on social organization. PLOS Biol 2007, 5:e62.

47. Nakamura A, Yasuda K, Adachi H, Sakurai Y, Ishii N, Goto S: Vitellogenin-6 is a major carbonylated protein in aged nematode, Caenorhabditis elegans. Biochem Biophys Res Comm 1999, 264:580-583.

48. Seehuus SC, Norberg K, Gimsa U, Krekling T, Amdam GV: Reproductive protein protects sterile honey bee workers from oxidative stress. Proc Natl Acad Sci USA 2006, 103:962-967.

49. Li Z, Zhang S, Liu Q: Vitellogenin functions as a multivalent pattern recognition receptor with an opsonic activity. PLOS ONE 2008, 3:e1940

50. Chen S, Li XC: Transposable elements are enriched within or in close proximity to xenobiotic-metabolizing cytochrome $\mathrm{P} 450$ genes. BMC Evol Biol 2007, 7:46.

51. Ronquist F, Huelsenbeck JP: MrBayes 3: Bayesian phylogenetic inference under mixed models. Bioinformatics 2003, 19:1572-1574.

52. Guindon S, Gascuel O: A simple, fast, and accurate algorithm to estimate large phylogenies by maximum likelihood. Syst Biol 2003, 52:696-704

53. Kumar S, Tamura K, Nei M: MEGA3:Integrated software for Molecular Evolutionary Genetics Analysis and sequence alignment. Brief Bioinform 2004, 5:150-163.

doi: 10.1186/1471-2148-10-142

Cite this article as: Chen et al., Duplication, concerted evolution and purifying selection drive the evolution of mosquito vitellogenin genes BMC Evolutionary Biology 2010, 10:142

\section{Submit your next manuscript to BioMed Centra} and take full advantage of:

- Convenient online submission

- Thorough peer review

- No space constraints or color figure charges

- Immediate publication on acceptance

- Inclusion in PubMed, CAS, Scopus and Google Scholar

- Research which is freely available for redistribution

Submit your manuscript at www.biomedcentral.com/submit
C Biomed Central 